Ciência Florestal, Santa Maria, v. 21, n. 1, p. 83-92, jan.-mar., 2011

\title{
HISTÓRICO DOS INCÊNDIOS FLORESTAIS NO PARQUE NACIONAL DO ITATIAIA
}

PAST AND PRESENT FOREST FIRES IN ITATIAIA NATIONAL PARK

Izar Aximoff ${ }^{1}$ Rodrigo de Carvalho Rodrigues ${ }^{2}$

RESUMO

Este trabalho objetivou a análise do histórico (1937-2008) de ocorrência de incêndios florestais do Parque Nacional do Itatiaia (PNI), primeiro parque do Brasil. Para isso, foi realizado um levantamento de informações no PNI, sobre o número total de incêndios, a extensão das áreas queimadas, os meses de maior incidência, a relação do fogo ao período de seca, a fauna e flora atingidas, os agentes causadores, as principais causas e as perícias dos incêndios. Foram identificados 323 incêndios (1937-2008). Apenas nos últimos sete anos foram queimados 5.724 ha, dentro e no entorno do Parque. As queimadas ocorreram sobretudo no inverno (90\%), período de seca, durante os meses de julho a outubro. As fitofisionomias com as maiores extensões atingidas foram os campos de altitude, ecossistema nativo da Mata Atlântica e restrito às montanhas do sudeste. De maneira geral, poucas informações foram identificadas em relação à fauna afetada, as causas e os agentes causadores dos incêndios, sendo que, por apenas duas vezes, foram realizadas perícias. Os dados revelaram a fragilidade do PNI diante dos incêndios florestais e a importância de serem implementadas ações de prevenção e combate, que garantam efetivamente a proteção integral dessa Unidade de Conservação.

Palavras-chave: incêndios florestais; Unidades de Conservação; campos de altitude.

\begin{abstract}
This study was conducted with the aim of evaluating the fire reports occurring in the Itatiaia National Park (INP) between 1937 and 2008 and aiming to show information about the total number of fires occurred, and the annual burnt areas, in relation with climate and biodiversity, the months of highest occurrence, the origins and causes of fires. A survey of 323 reports of forest fires showed the highest incidence of forest fires in the months of winter, during the dry season, between July and October. The most affected vegetation was that of the "campos de altitude" (high-altitude grasslands), a native ecosystem of Atlantic Rainforest restricted to the isolated southeastern high peaks and plateaus. Most of the fires had unknown origins and causes, and only twice were examinations by experts carried out. Data revealed INP fragility against forest fires and the importance and the need of Forest Fire Privation and Control Plans for effective biodiversity protection.
\end{abstract}

Keywords: wildfires; Conservation Units; high-altitude grasslands.

\section{INTRODUÇÃO}

O fogo na Mata Atlântica é uma ferramenta antiga, utilizada pelos caçadores-coletores a mais de 10 mil anos, para eliminar a vegetação lenhosa na limpeza de terreno, para auxiliar na caça e na preparação de alimentos. Seu uso agressivo e contínuo nos séculos XVIII e XIX, para abrir espaços na floresta para criação de gado e para o plantio de café, foi muito danoso pela elevada frequência e pelas grandes extensões (DEAN, 2002). Assim, o fogo progressivamente vem modelando a paisagem, modificando a estrutura, a composição, o poder de regeneração de comunidades vegetais (SILVA et al., 2005), reduzindo drasticamente as florestas e outros ambientes naturais, sobretudo do Bioma Mata Atlântica (SAFFORD, 2001; RIBEIRO, 2002). Atualmente, esse bioma se encontra

1. Biólogo, M.Sc., Professor do Departamento de Ciências Ambientais, Instituto de Florestas, Universidade Federal Rural do Rio de Janeiro, BR 465, km 07, CEP 23890-000, Seropédica (RJ). izar.aximoff@gmail.com

2. Geógrafo, M.Sc., Doutorando do Programa de Geoquímica, Universidade Federal Fluminense, Rua: Outeiro São João Baptista s/n, CEP 24020-141, Niterói (RJ).rodrigorodriguesgeo@gmail.com

Recebido para publicação em 2/09/2009 e aceito em 2/06/2010. 
reduzido a cerca de $16 \%$ de sua cobertura florestal original (RIBEIRO et al., 2009) e a maior parte dos remanescentes florestais está sob constante pressão das atividades humanas (CÂMARA, 1996).

Assim, para entender o estado atual da Mata Atlântica é preciso levar em consideração o histórico do fogo. Na região do Vale do Rio Paraíba do Sul, sul do estado do Rio de Janeiro, onde o Parque Nacional do Itatiaia está localizado, a prática do fogo vem sendo realizada desde o século XVIII. Segundo Dúsen (1955), durante excursão em 1902-1903, em que descreveu aspectos botânicos e ecológicos, mencionou que anualmente os campos e grandes áreas eram queimados, sobretudo para manejo de pastagem natural para o gado. Por sua vez, Brade (1956) mencionou que a flora primitiva da região de Itatiaia sofreu bastante com a influência humana, especialmente na época da existência de uma colônia agrícola, anos de 19081918, quando queimadas propositais ou acidentais eram frequentes em pastagens, campos nativos e florestas. Dessa maneira, pode-se considerar que não só a vegetação mas toda a biodiversidade que encontramos atualmente no Parque Nacional do Itatiaia resulta desse longo histórico de convívio com o fogo.

Além do Parque Nacional do Itatiaia, inúmeras Unidades de Conservação (UC) sofrem anualmente com grandes incêndios (LIMA, 2000; IBAMA, 2002), sobretudo em consequência de atividades antrópicas (MEDEIROS, 2002). Tais incêndios podem causar danos a vários componentes do ambiente, como, por exemplo, a biodiversidade (KOPROSKI et al., 2004), com isso, tais danos geram enormes prejuízos do ponto de vista científico, ambiental e financeiro (OLIVEIRA et al., 2000). Nesse sentido, estudos que identifiquem, por exemplo, o regime de fogo, conceituado como o padrão de intensidade, frequência e sazonalidade (AGEE, 1993), as causas, os agentes causadores, os lugares de ocorrência e a extensão das áreas queimadas são de extrema relevância para contribuir no desenvolvimento de ações de prevenção e combate aos incêndios nas UC.

O presente trabalho analisa as informações sobre o histórico dos incêndios ocorridos no Parque Nacional do Itatiaia (PNI) e no seu entorno legal (10 km ao redor de seus limites), com a finalidade de apoiar a implementação do Plano. Operativo de Prevenção e Combate aos Incêndios no Parque Nacional do Itatiaia.

\section{MATERIAIS E MÉTODOS}

\section{Área de Estudo}

O Parque Nacional do Itatiaia (PNI) (22 ${ }^{\circ} 15^{\prime}$ e $22^{\circ} 30^{\prime} \mathrm{S}$; $44^{\circ} 30^{\prime} \mathrm{e} 44^{\circ} 45^{\prime} \mathrm{W}$ ) localizado no sul do Rio de Janeiro (RJ) e ao sul de Minas Gerais (MG), abrange uma área de 28.156 hectares. Seu território geográfico, localizado na porção mais elevada da Serra da Mantiqueira está compreendido dentro dos seguintes municípios: Itatiaia e Resende (RJ), Bocaína de Minas e Itamonte (MG). Desses municípios, Itatiaia e Itamonte são os que apresentam a maior parte de seu território dentro da UC, respectivamente, 35 e $22 \%$.

Atualmente o PNI vem enfrentando diversos problemas relacionados sobretudo às queimadas, à situação fundiária não regularizada, ao parcelamento irregular do solo em especial seu entorno, ao turismo desordenado, à caça e ao extrativismo ilegal especialmente de palmito.

O rico patrimônio biótico e geomorfológico fizeram do PNI o primeiro parque a ser criado no Brasil, pelo Decreto Federal n. 1713, de 14 de junho de 1937 (IBDF, 1982). A importância geológica se deve, em parte, às elevações rochosas da parte alta onde está localizado o Pico das Agulhas Negras, o quinto ponto mais alto do Brasil (2.792 metros de altitude) e ao tipo raro de rochas (nefelina-sienito) que as formam (SEGADAS-VIANNA, 1965). A importância biológica está relacionada ao extenso gradiente altitudinal de mais de 2.000 metros (600 a $2792 \mathrm{~m}$ ), que possibilita diferentes fisionomias vegetacionais, tais como floresta montana, floresta alto montana e campos de altitude (SEGADASVIANA e DAU, 1965).

Além disso, outras fitofisionomias são encontradas e estas são mais relacionadas com a presença de alguma espécie, como por exemplo a floresta alto montana com Araucária, ou pela presença de espécies em ambientes específicos, como brejos de altitude ou afloramentos rochosos (RIBEIRO, 2002). Existem também as áreas alteradas, como florestas em regeneração e pastagens (RICHTER, 2004). A riqueza de ambientes propicia a diversidade de espécies tanto da flora quanto da fauna: no PNI estão presentes diversas espécies endêmicas e ameaçadas (BRADE, 1956; GEISE et al., 2004; MMA, 2008a).

Neste estudo, a formação florestal do PNI é tratada no conceito da floresta atlântica (OLIVEIRA-FILHO e FONTES, 2000), sendo

Ci. Fl., v. 21, n. 1, jan.-mar., 2011 
também reconhecida como floresta ombrófila densa, segundo sistema de classificação do IBGE (VELOSO et al., 1991).

O clima no PNI apresenta certa estacionalidade relacionada às fortes chuvas, de outubro a abril (estação chuvosa), e ao período de seca, de maio a setembro (estação seca). Nas altitudes mais baixas, em torno de $1.000 \mathrm{~m}$, a precipitação média anual varia entre 1.500 a 1.800 $\mathrm{mm}$, de acordo com a última normal climatológica (1961-1990). Nos Campos de Altitude no Rio de Janeiro, a precipitação média anual varia de 2.000 a $3.000 \mathrm{~mm}$ (SAFFORD 1999).

\section{Coleta e Analise de Dados}

Os dados dos incêndios florestais no PNI e seu entorno foram obtidos mediante a busca e a análise de documentos (ofícios, relatórios, memorandos e autos de infração) arquivados na $\mathrm{UC}$, sendo que o registro mais antigo encontrado foi no ano de criação da UC (1937) e os dados mais atuais foram até o fim de 2008. A partir de 2001, foi adotado pelo PNI o formulário específico para o registro de ocorrência de incêndio florestal (ROI). As informações coletadas a cerca do número total de incêndios, da extensão das áreas atingidas, dos meses de maior incidência durante os anos, da relação do fogo com o período de seca, da fauna e flora atingidos, dos agentes causadores, as principais causas dos incêndios e das perícias realizadas foram organizadas em planilhas e posteriormente analisadas. $\mathrm{O}$ padrão de ocorrência dos incêndios foi utilizado para identificar possíveis relações com os dados de precipitação da região. Devese salientar que as informações sobre tamanho das áreas queimadas, obtidas nos documentos e mesmo nos ROIs, podem não ser precisas. Isso se deve à estimativa das áreas queimadas sem o uso sistemático de instrumentos e técnicas adequadas (GPS e imagens de satélites).

\section{RESULTADOS E DISCUSSÃO}

\section{Total de ocorrências}

Foram identificados relatos de 323 incêndios distribuídos em 36 anos não consecutivos (Tabela 1). Comparando-se o número de registros de incêndios com o de outras UCs, mesmo aquelas com área maior, fica evidente o número elevado de ocorrências no PNI. Por exemplo, no Parque Nacional da Serra da Bocaina (PNSB), unidade de mesma categoria mais próxima ao PNI $(70 \mathrm{~km})$, os registros históricos somam 101 ocorrências (MMA, 2001). Mesmo, comparando-se esses dados para anos mais recentes, a abundância de registros no PNI se destaca. No Parque Nacional de Ilha Grande (PNIG), 78.875 ha no Paraná, entre 19992003, ocorreram 52 incêndios (KOPROSKI et al., 2004) enquanto no PNI nesse mesmo período, foram 81. No Parque Nacional da Chapada dos Veadeiros (PNCV), 65.514 ha em Goiás, entre 1992-2003, foram 70 ocorrências (FIEDLER et al., 2006), valor 3,7 vezes menor do que o registrado no PNI. Nesse sentido, o fato de o parque estar inserido no Vale do Paraíba do Sul, identificada como a primeira das sete unidades geomorfológicas estaduais em relação ao número absoluto de focos de incêndio (TANIZAKI e BOHRER, 2009), pode ser determinante para os elevados valores identificados.

TABELA 1: Número anual de incêndios no período de 1937-2008 no Parque Nacional do Itatiaia (PNI). TABLE 1: Number of fires from 1937-2008 at Itatiaia National Park (INP).

\begin{tabular}{cccccccc}
\hline Ano & Número & Ano & Número & Ano & Número & Ano & Número \\
\hline 1937 & 2 & 1961 & 1 & 1989 & 24 & 2000 & 1 \\
1943 & 1 & 1963 & 2 & 1990 & 6 & 2001 & 16 \\
1945 & 1 & 1971 & 1 & 1991 & 5 & 2002 & 18 \\
1951 & 3 & 1979 & 2 & 1992 & 1 & 2003 & 43 \\
1952 & 4 & 1980 & 1 & 1993 & 4 & 2004 & 19 \\
1955 & 2 & 1981 & 2 & 1995 & 9 & 2005 & 16 \\
1957 & 1 & 1984 & 1 & 1996 & 1 & 2006 & 49 \\
1959 & 1 & 1987 & 1 & 1997 & 4 & 2007 & 19 \\
1960 & 1 & 1988 & 1 & 1999 & 3 & 2008 & 57 \\
\hline
\end{tabular}


O PNI é contornado por municípios historicamente reconhecidos pelas atividades agropecuárias e onde atualmente o uso e ocupação do solo são desordenados. Uma das conseqüências disso reside nas grandes extensões de pastagens e áreas alteradas dentro e no entorno da UC (RICHTER, 2004), identificadas então como potenciais fontes combustíveis para os incêndios, que cada vez mais vem colocando em risco a biota do PNI e a vida dos próprios moradores da região. De forma geral, no Brasil, o fogo é utilizado há centenas de anos, como ferramenta para diversos fins (DEAN, 2002), sendo responsável pela grande devastação de vários biomas (NEPSTAD et al., 1999; MEDEIROS, 2002), dentre eles a Mata Atlântica (DEAN, 2002), que outrora cobria todo o litoral brasileiro. Com isso, a maior parte dos remanescentes florestais atualmente se encontram em UCs, que continuam sob pressão das atividades humanas (CÂMARA, 1996).

\section{Extensão atingida anualmente}

Foram identificados 193 registros que apresentaram a extensão da área queimada. Durante o período de 2001 a 2008, foram queimados 3.064 ha dentro do PNI e 2.664 ha em seu entorno. De três em três anos desde 2001, ocorreram grandes incêndios no PNI (Figura 1), sendo que no último em 2007, o fogo consumiu 800 ha da área mais visitada do parque, a região do Pico das Agulhas Negras. Os maiores incêndios foram, respectivamente, em 1988
(4.000 ha) e 1984 (1.200 ha). Contudo o incêndio mais duradouro, e provavelmente o maior da história ocorreu em 1963, permanecendo ativo por cerca de 50 dias. Relatos de moradores do parque afirmam que a área atingida foi de aproximadamente 10.000 ha. Grandes incêndios têm sido registrados em outros Parques Nacionais, como no da Ilha Grande (KOPROSKI et al., 2004), no da Chapada dos Veadeiros (FIEDLER et al., 2006) e no da Chapada dos Guimarães (PNCG) (MMA, 2007). No Brasil, de acordo com Lima (2000), cerca de 400 mil hectares são queimados anualmente em UCs.

$\mathrm{O}$ setor norte do PNI, localizado em Itamonte, na Bacia do Rio Aiuruoca, próximo à região queimada de 2007, é o que apresenta a maior incidência de incêndios. De fato, trata-se do setor com o maior potencial para ocorrência de incêndios (SILVA et al., 2007) visto que é muito impactado pela pecuária promovida por comunidades com situação fundiária irregular e onde existe grande parte das áreas com vegetação alterada dentro dos limites da UC. Situação similar ocorre no Parque Estadual da Serra do Brigadeiro (PESB), em Minas Gerais, onde os impactos das queimadas são grandes, e devem-se sobretudo ao fato de o entorno da UC ser habitado por pequenos produtores rurais que utilizam o fogo como principal ferramenta (BONFIM et al., 2003). Esse cenário aponta que a situação fundiária não regularizada dentro das UCs, de acordo com Medeiros e Fiedler (2004), aumenta a pressão sobre a preservação dos seus recursos naturais. Assim, identificamos que a regularização

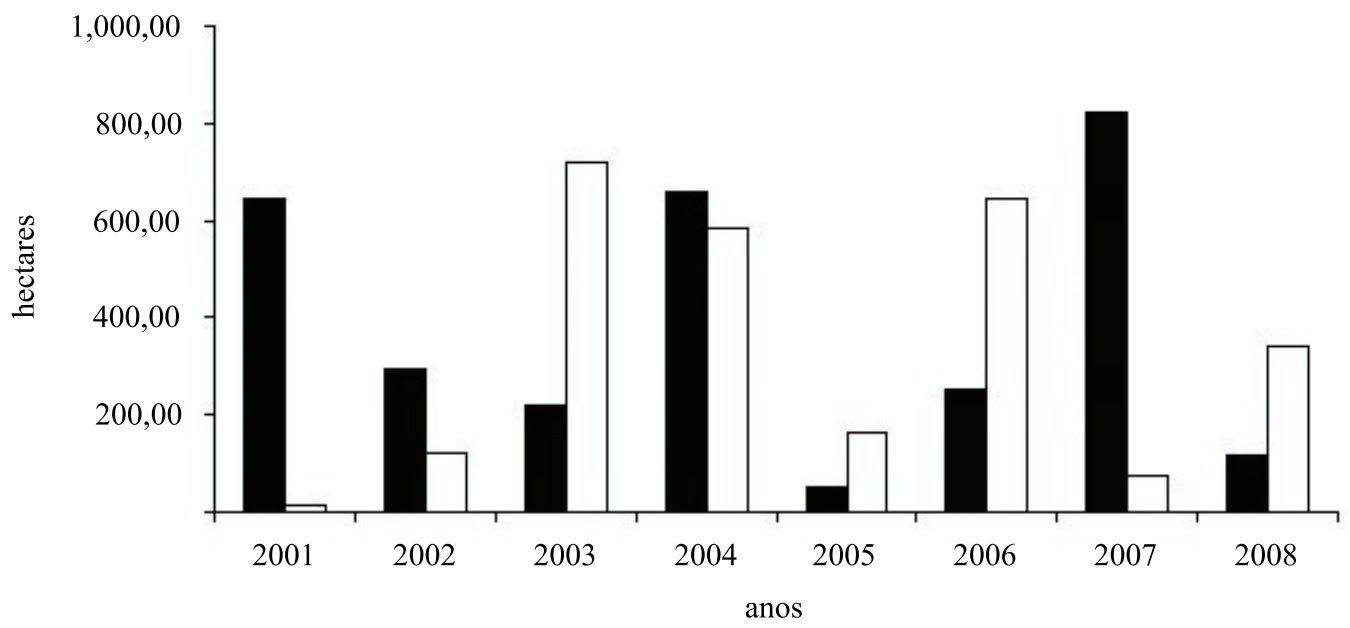

FIGURA 1: Áreas (ha) atingidas por incêndios no período de 2001 a 2008 no PNI (barras pretas) e no seu entorno (barras brancas).

FIGURE 1: Burnt areas (ha) from 2001 to 2008 at INP (black bars) and its surrounding areas (white bars).

Ci. Fl., v. 21, n. 1, jan.-mar., 2011 
da situação fundiária interna e do entorno do Parque Nacional do Itatiaia é ação fundamental para a prevenção dos incêndios nessa UC.

De fato, existem muitos casos comprovando o impacto que as populações estabelecidas no interior ou no entorno das UC podem causar com o uso indevido do fogo. Por exemplo, no Parque Nacional da Serra dos Órgãos (PNSO), no Rio de Janeiro, em 2004, um incêndio originado em uma propriedade do entorno da UC queimou cerca de 250 ha (MMA, 2008b). Uma das perspectivas para resolver essa questão, é envolver o Ministério Público Federal, a administração das UC e moradores para assinatura de Termos de Compromisso a fim de evitar a utilização do fogo nas UC, sem a devida autorização dos órgãos ambientais, como estabelece o Decreto n. 2.661 de julho de 1998. A realização de acordos com proprietários, que criam gado no Parque Nacional da Serra do Cipó, se mostrou uma ferramenta viável no combate aos incêndios naquela $\mathrm{UC}$, na medida em que os proprietários retiraram seus animais do interior desta e passaram a responder pela ocorrência de fogo na área de sua responsabilidade o que contribui para a redução da frequência e extensão dos incêndios (RIBEIRO et al., 2006).

Uma característica identificada neste estudo e frequente em muitos outros, tem sido o fato de que o número de incêndios não está diretamente relacionado com a extensão da área queimada. No PNIG, por exemplo, os 17 incêndios ocorridos em 2002 atingiram 27.000 ha e em 2003 apenas seis incêndios atingiram 37.000 ha (KOPROSKI et al., 2004). No Parque Nacional de Yelowstone, em Wyoming nos Estados Unidos, no único incêndio que ocorreu em 1988, 40\% do parque foi consumido (TURNER et al., 1994). Em Itatiaia, em 1988, ocorreu apenas um incêndio que atingiu 4.000 ha, área maior do que a soma de toda extensão atingida pelos 237 incêndios ocorridos no PNI e em seu entorno de 2001 a 2008. Esses dados revelam que tão importante quanto diminuir a ameaça do elevado número de incêndios nas UCs, é controlar de forma eficiente os incêndios de grandes proporções que, na maioria das vezes, são propositais, tendo em vista que incêndios causados por raios, tipo raro em Itatiaia, são conhecidos por serem de limitada extensão, em média 500 ha de área queimada (RAMOS-NETO, 2000; MEDEIROS, 2002).

\section{Total mensal de ocorrências, de áreas atingidas e relação com a seca}

Os meses mais críticos, com maior ocorrência de incêndios, foram julho, agosto, setembro e outubro, e o pico de ocorrências foi em agosto (32,8\%) (Figura 2). As maiores extensões de áreas atingidas pelo fogo ocorreram nos meses citados anteriormente e a maior extensão foi em setembro (5.284 ha). Esses dados, segundo Agee (1993), permitem identificar o regime do fogo no PNI, que apresentou padrão similar ao apresentado no estado entre 2000-2006, quando as maiores ocorrências foram nos meses de julho

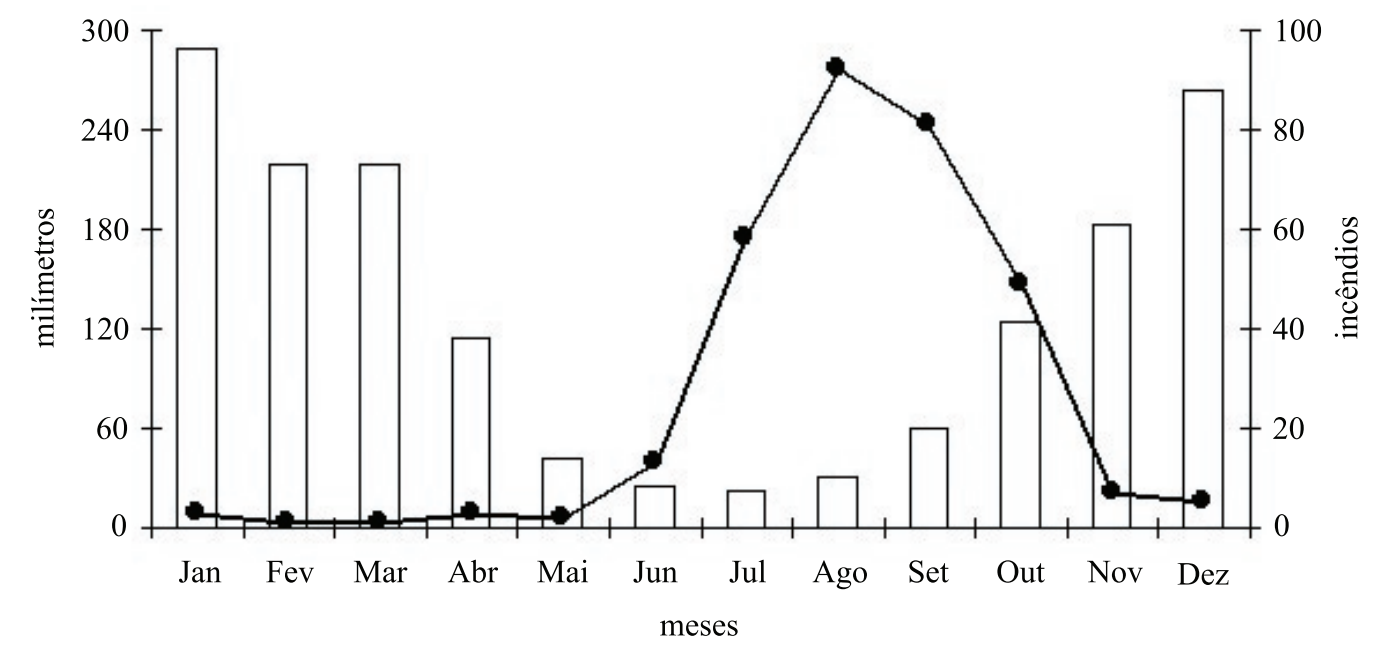

FIGURA 2: Precipitação mensal da última normal climática de 1961 a 1990 (barras brancas) e ocorrência de incêndios mensais no período de 1937 a 2008 (linha preta).

FIGURE 2: Precipitation of the last climatic normal from 1961 to 1990 (white bars) and the occurrence of fire occurrence from 1937 to 2008 (black line). 
a outubro (TANIZAKI e BOHRER, 2009). De fato, os incêndios no Brasil ocorrem nesse período (SOARES, 1989; SOARES e SANTOS, 2002). Pode-se perceber a sobreposição entre os meses mais críticos para o fogo e a estação de seca (Figura 2) o que pode estar relacionado ao período de maior atividade rural em todo Brasil (SOARES, 1989), quando o fogo é utilizado como a ferramenta para a renovação da pastagem, por exemplo. Portanto, as medidas de prevenção aos incêndios devem ser implementadas nos meses anteriores ao período crítico e reforçadas durante este.

\section{Tipo de vegetação e fauna atingidas}

Das 149 citações da vegetação atingida, foi possível identificar e classificar cinco tipos de fitofisionomias (Tabela 2). A maioria dos incêndios ocorreu em área de pastagens (49\%), contudo a maior extensão atingida foi nos campos de altitude $(49,6 \%)$, tipo de fisionomia nativa, que surge acima do limite altitudinal das florestas que, em Itatiaia, está em torno dos 1.800.m (RIBEIRO 2002). Nas altitudes mais elevadas do Maciço do Itatiaia, há o predomínio de pastagens em diversas localidades conforme identificou Richter (2004), e que em determinados trechos são conectadas diretamente com os campos de altitude (obs.pess.). A altitude média identificada para áreas atingidas por incêndios, em 179 registros, foi $1505 \mathrm{~m}$ ( $\pm 575 \mathrm{~m})$. Segundo Santos (2003) mais de 60\% do PNI está acima dos 1.600 metros de altitude. Esses resultados comprovam que além do Vale do Rio Paraíba do Sul, que está em média a $500 \mathrm{~m}$ de altitude, apresentarse como área com inúmeras ocorrências para o estado (TANIZAKI e BOHRER, 2009), pode-se considerar que o fogo também é comum no Maciço do Itatiaia.

Considerando o uso do solo, as áreas do estado do Rio de Janeiro mais atingidas pelo fogo foram as pastagens, seguidas por áreas agrícolas e em menor escala por florestas (TANIZAKI e BOHRER, 2009). Soares e Santos (2002) registraram uma evolução no perfil dos incêndios no Brasil, em relação ao tipo vegetacional atingido, que inicialmente eram os cerrados, campos e capoeiras, passando mais recentemente para a queima de florestas nativas, o que demonstra um recorrente caráter destrutivo da biodiversidade. No PNI, as áreas de florestas também foram afetadas, mas em proporções pequenas (tabela 2). Contudo, como identificado anteriormente os campos de altitude, tipo de ecossistema marginal da Mata Atlântica no sudeste (SCARANO, 2002), que em Itatiaia, abriga cerca de 400 espécies de plantas vasculares sendo $11 \%$ destas consideradas localmente endêmicas (MARTINELLI et al., 1989), estão sofrendo com a constante pressão do fogo. Dessa forma, pode-se considerar que a atividade do fogo ainda permanece associada aos processos de desmatamento de remanescentes florestais e de ecossistemas raros e continua contribuindo com a degradação da Mata Atlântica.

De forma geral a cada incêndio nos campos de altitude, praticamente toda a cobertura vegetal desaparece (obs.pess.). Segundo Safford (2001) em campos de altitude queimados nos Parques Nacionais do Caparaó, no Espírito Santo, e no PNSO, as espécies do estrato herbáceo são aquelas que mais rapidamente se restabelecem, em detrimento das espécies lenhosas, que podem levar até 15 anos para se regenerarem. Assim, a alta frequência do fogo numa mesma região pode levar a perda irreversível de parte dos recursos genéticos, antes mesmo de conhecermos seu potencial (SILVA, 2001). No PNI, os incêndios vêm progressivamente modificando a paisagem, ampliando os limites das pastagens com a queima de florestas alto-montanas e dos campos de altitude, modificando as comunidades vegetais, mesmo aquelas que o fogo não agiu diretamente (RIBEIRO et al., 2007), e por último, fazendo com as espécies ameaçadas se tornem cada vez mais raras e difíceis de serem encontradas, como é o caso de Hindsia glabra (Rubiaceae), outrora comum e atualmente está representada por poucos indivíduos isolados e restritos a pequenos espaços entre grandes blocos de pedra (obs.pess.).

A fauna também é afetada pelos incêndios,

TABELA 2: Frequência de queimadas e área atingidas (ha) em cinco tipos de vegetação no PNI e em seu entorno.

TABLE 2: Fire frequency and burnt area of five vegetation types at INP and surrounding areas.

\begin{tabular}{lcc}
\hline Tipo Vegetacional & n. $(\%)$ & ha $(\%)$ \\
\hline Campos de Altitude & $43(28,9)$ & $2937,3(49,6)$ \\
Pastagem e Capoeira & $73(49,0)$ & $1944,8(32,9)$ \\
Floresta Altomontana & $16(10,7)$ & $139,0(2,3)$ \\
Floresta & $15(10,1)$ & $897,5(15,2)$ \\
Eucaliptal e Candeial & $2(1,3)$ & $1,7(0,0)$ \\
\hline
\end{tabular}


contudo, no Brasil, são poucos os estudos que avaliam essa questão (ABREU et al., 2004; KOPROSKI et al., 2006). No PNI, apenas em nove incêndios foram citados animais mortos, sendo que 50\% destes foram cobras e o restante foram lagartos, pássaros e pequenos mamíferos. A elevada mortalidade de cobras também foi observada no PNIG (KOPROSKI et al., 2006), contudo, assim como no PNI, em poucas ocorrências de incêndio esses animais foram encontrados, o que pode estar relacionado ao sucesso de fuga dos animais ou a presença de aves de rapina e carniceiros que poderiam consumir os animais atingidos (KOPROSKI et al., 2006), ou mesmo, por causa da baixa percepção em relação à busca desses animais pela equipe de combate aos incêndios. Os impactos sobre fauna devem ser melhor estudados e avaliados principalmente porque na região de campos de altitude existem animais lentos e que utilizam a vegetação campestre como abrigo, como por exemplo, o pequeno sapo endêmico Melanophryniscus moreirae e o lagarto Mabuya dorsivittata que seriam facilmente atingidos pelos incêndios.

\section{Causas, agentes causadores e perícia}

A maior parte dos incêndios teve causa e agentes desconhecidos $(88,2 \%)$, sendo que do restante das ocorrências, $82,6 \%$ foram provocadas por humanos, sendo a maior parte dessas, para limpeza e renovação da pastagem $(42,8 \%)$ (Tabela 3). De acordo com Soares e Santos (2002), a principal causa dos incêndios florestais no país é a limpeza da vegetação para renovação da pastagem. Por isso e em razão da baixa incidência de incêndios de causas naturais na região, é provável que os incêndios qualificados como de causa e agentes causadores desconhecidos sejam de origem humana e para a atividade rural. A falta de informações sobre a causa e o agente causador é consequência da precariedade do sistema de perícias. Apenas em dois incêndios ocorridos, foi realizada perícia, fato comumente registrado em outras UCs, onde a quantidade e qualidade das perícias são abaixo do esperado (OLIVEIRA et al., 2000). De maneira similar, no estado do Paraná, do total de 15.890 ocorrências, apenas 67 tiveram as causas registradas (VOSGERAU et al., 2006). As perícias são importantes, pois possibilitam a identificação da origem e das causas dos incêndios, permitindo a realização de um diagnóstico para a remediação do problema.

Outra questão importante diz respeito aos incêndios criminosos ou causados por incendiários que ocorreram no PNI e também em outras UCs (KOPROSKI et al., 2004; MEDEIROS e FIEDLER, 2004; MMA, 2007; Costa et al. 2009). Esse fato apresenta dois aspectos relativos ao uso fogo. Primeiro, relacionado à visão que a população local tem das UCs que, em alguns casos, é negativa e pode estar incentivando as ocorrências propositais desse tipo de distúrbio. Por exemplo, a simples transformação da área da Serra da Bocaína em Parque Nacional resultou em aumento do fogo de origem criminosa na região (MMA, 2001). $\mathrm{O}$ segundo aspecto trata do fato dos métodos alternativos ao fogo serem de conhecimento da maioria dos ruralistas, conforme identificaram Bonfim et al. (2003), mas que em razão do elevado custo de maquinário para tal, e ao imediatismo, o fogo continua sendo a técnica mais empregada (COSTA et al., 2009). Com isso, pode-se deduzir a existência de deficiências nas campanhas educativas, particularmente quanto ao trabalho de esclarecimento da importância das UCs junto às populações que residem dentro ou no entorno e também a falta de incentivos e fomento destas às atividades alternativas ao fogo.

TABELA 3: Agentes causadores e causas dos incêndios de 1937 a 2008 no PNI e entorno.

TABLE 3: Agents and causes of fires from 1937 to 2008 at INP and surrounding areas.

\begin{tabular}{cccccc}
\hline $\begin{array}{c}\text { Agentes } \\
\text { causadores/ Causas }\end{array}$ & $\begin{array}{c}\text { Limpeza/ } \\
\text { Renovação } \\
\text { de pasto }\end{array}$ & Desconhecido & Criminoso & $\begin{array}{c}\text { Fogos de } \\
\text { artificio }\end{array}$ & Natural \\
\hline Morador & 9 & 2 & 2 & & \\
Transeunte & 1 & 1 & 1 & & \\
Indeterminado & 172 & 2 & 1 & 2 \\
Incendiário & & 2 & & & 2 \\
Raio & & & 2 & & \\
\hline
\end{tabular}




\section{CONCLUSÃO}

Este estudo revela a fragilidade do Parque Nacional do Itatiaia diante dos incêndios que anualmente atingem a UC. Torna-se necessário o desenvolvimento de ações planejadas e participativas entre os gestores da UC e moradores que envolvam assistência técnica específica, educação ambiental, divulgação dos impactos do fogo e dos benefícios dos métodos opcionais, além da legislação que rege o uso do fogo, a fim de evitar danos ao ambiente e multas aos moradores. Paralelamente, deve-se realizar o zoneamento das regiões mais críticas aos incêndios que deveriam receber prioridade nas ações de prevenção, fiscalização e controle, por meio da implementação do Plano Operativo. Essas ações devem garantir à área do PNI e ao seu entorno a efetiva proteção, de modo a permitir que importantes serviços ambientais, que os ecossistemas naturais proporcionam à sociedade continuem existir. Adicionalmente a essas ações de prevenção e proteção, consideramos importante a realização de estudos que detectem a ocorrência de paleoincêndios por meio da contagem dos microcarvões depositados nos registros sedimentares e turfosos das áreas brejosas e lacustres em ambientes do parque.

\section{AGRADECIMENTOS}

Aos servidores públicos federais doICMBio/ PNI, Gustavo Tomzhisnki (Gerente de Fogo), pela disponibilização dos ROI, e Léo Nascimento (Gerente de Pesquisa), pela criação da Comissão do Fogo em 2007. À Lucia Teixeira (Prefeitura de Resende), à Haroldo Simon (Prefeitura de Itatiaia) e à André Vieira (Ministério da Agricultura, Pecuária e Abastecimento), pelo apoio no levantamento dos dados históricos dos incêndios, e à Gerson Luiz Selle (Revista Ciência Florestal), Giovanna Cappelli e Marina Torres pelas sugestões, críticas e contribuições para este manuscrito.

\section{REFERÊNCIAS BIBLIOGRÁFICAS}

ABREU, K. C.; KOPROSKI, L. P.; KUCZACH, A. M. Grandes felinos e o fogo no parque nacional de ilha grande, brasil. Floresta, Curitiba, v. 34, n. 2, p. 163-167. maio/ago. 2004.

AGEE, J. K. Fire Ecology of Pacific Northwest Forests. New York: Island Press, 1993.

BONFIM, V. R.; RIBEIRO, G. A.; SILVA, E.
Diagnóstico do uso do fogo no entorno do Parque Estadual da Serra do Brigadeiro (PESB), MG. Revista Árvore, Viçosa, v. 27, n. 1, p. 87-94. jan/ fev. 2003.

BRADE, A.C. A flora do Parque Nacional do Itatiaia. Boletim do Parque Nacional do Itatiaia, n. 5, p. 1-114. 1956.

BRASIL. Ministério do Meio Ambiente. Mapeamento da Cobertura Vegetal do Bioma Mata Atlântica. 2006. Projeto Integrado para Mapeamento da Cobertura Vegetal do Brasil na escala 1:250.000.

BRASIL. Ministério do Meio Ambiente. Plano de Manejo do Parque Nacional da Serra da Bocaina - RJ. 2001. Disponível em http://www.icmbio.gov. br/parna bocaina/index.php?id menu $=50$

BRASIL. Ministério do Meio Ambiente. Plano Operativo de Prevenção e Combate aos Incêndios Florestais do Parque Nacional da Chapada dos Guimarães - MT. 2007.

BRASIL. Ministério do Meio Ambiente. Lista

Oficial das Espécies da Flora Brasileira Ameaçadas de Extinção. 2008a.

BRASIL. Ministério do Meio Ambiente. Plano de Manejo do Parque Nacional do Parque Nacional da Serra dos Órgãos - RJ. 2008b. Disponível em http://www.icmbio.gov.br/parnaso/index.php?id_ menu $=135$

CÂMARA, I. G. Plano de ação para a Mata Atlântica: roteiro para a conservação da sua biodiversidade. Reserva da Biosfera da Mata Atlântica. São Paulo, v. 4, p. 70. 1996.

COSTA, E. P.; DEAN, W. A Ferro e Fogo: A história da devastação da Mata Atlântica brasileira. São Paulo: Companhia das Letras, 2002. p. 484.

DUSÉN, P. K. H. Contribuições Para a Flora Do Itatiaia. Boletim do Parque Nacional do Itatiaia, v. 4, p. 6-91. 1955.

FIEDLER, N. C.; MERLO, D. A.; MEDEIROS, M. B. Ocorrência de incêndios florestais no Parque Nacional da Chapada dos Veadeiros, Goiás. Ciência Florestal, Santa Maria, v. 16, n. 2, p. 153-161, jul./ dez. 2006.

GEISE, L.; PEREIRA, L. G.; BOSSI, D. E. P. Pattern of elevational distribution and richness of non volant mammals in Itatiaia national park and its surroundings, in southeastern brazil. Brazilian Journal of Biology, v. 64, n. 3B, p. 599-612. Aug. 2004.

IBAMA - Instituto Brasileiro de Meio Ambiente e Recursos Renovaveis. Relatório de Ocorrência de Incêndios Florestais. Documento Técnico. 
PREVFOGO. 2002.

KOPROSKI, L.; BATISTA, A. C.; SOARES, R. $\mathrm{V}$. Ocorrências de incêndios florestais no Parque Nacional de Ilha Grande - Brasil. Floresta, Curitiba, v. 34, n. 2, p. 193-197. mai/ago. 2004

KOPROSKI, L. et al. Impactos do fogo sobre serpentes (Squamata) no Parque Nacional de Ilha Grande (PR/MS), Brasil. Arquivos Ciência. Veterinária. Zoológica Unipar, Umuarama, v. 9, n. 2, p. 129-133. 2006.

LIMA, G. S. Os incêndios florestais no Estado de Minas Gerais. Revista Ação Ambiental, v. 2, n. 12, p. 15-18. 2000.

MARTINELLI, G.; BANDEIRA, J.; BRAGANÇA, J. O. Campos de altitude. Rio de Janeiro: Index. 1989.

MEDEIROS, M. B. Manejo de Fogo em Unidades de Conservação do Cerrado. Boletim do Herbário Ezechias Paulo Heringer, v. 10, p. 75-88. 2002. MEDEIROS, M. B.;FIEDLER, N. C. Incêndios florestais no Parque Nacional da Serra da Canastra: desafios para a conservação da biodiversidade. Ciência Florestal, Santa Maria, v. 14, n. 2, p $157-$ 168. jul/dez. 2004

NEPSTAD, D. C.; MOREIRA, A. G.; ALENCAR, A. A. Flames in the Forest: origins, impacts and alternatives to Amazonian fires. Brasília: The Pilot Program to Conservation the Brazilian Rain Forest, 1999. 90 p.

OliveIRA, D. S.; BATISTA, A. C.; MILANO, M. S. Fogo em Unidades de Conservação. In: CONGRESSO BRASILEIRO DE UNIDADES DE CONSERVAÇÃO, 2., 2000, Campo Grande Anais ... Campo Grande, 2000. p. 200-207. v. 2.

OLIVEIRA-FILHO, A. T.; FONTES, M. A. L. Patterns of floristic differentiation among Atlantic forests in southeastern Brazil, and the influence of climate. Biotropica, v. 32, n. 4b, p. 793-810. 2000. RIBEIRO, K. T. Estrutura, Dinâmica e Biogeografia das Ilhas de Vegetação Rupícola do Planalto do Itatiaia, RJ. 2002. 116 f. Tese (Doutorado em Ecologia)-Universidade Federal do Rio de Janeiro, Rio de Janeiro, 2002.

RIBEIRO, K. T.; MADEIRA, J. A.; COLLET, $H$. D. Conquistas e desafios na prevenção e combate a incêndios em vegetações abertas no interior e entorno do Parque Nacional da Serra do Cipó, sudeste do Brasil. In: CONGRESSO PARA LA PREVENCIÓN Y COMBATE A INCÊNDIOS FLORESTALES Y PASTIZALES DEL MERCOSUR, 2., 2006, Mendoza. Anales... Mendoza, 2006.
RIBEIRO, K. T.; MEDINA, B. M. O.; SCARANO, F. R. Species Composition and Biogeographic Relations of the Rock Outcrop Flora on the High Plateau of Itatiaia, Se-Brazil, Revista Brasileira de Botânica, v. 30, n. 4, p. 623-639. out/dez. 2007. RIBEIRO, M. C.; METZGER, J. P.; MARTENSEN, A. C. The Brazilian Atlantic Forest: How much is left, and how is the remaining forest distributed? Implications for conservation, Biological Conservation, v. 142, p. 1141-1153. June 2009.

RICHTER, M. Geotecnologias no Suporte ao Planejamento e Gestão de Unidades de Conservação Estudo de caso: Parque Nacional do Itatiaia. 2004. 162 f. Dissertação (Mestrado em Geografia)-Universidade Federal do Rio de Janeiro, Rio de Janeiro, 2004.

SAFFORD, H. D. Brazilian Paramos II. Macro- and Mesoclimate of the Campos de Altitude and affinities with High Mountain Climates of the Tropical Andes and Costa Rica. Journal of Biogeography, v. 26, n. 4, pp. 713-737. July 1999.

SAFFORD, H. D. Brazilian Paramos III - Patterns and rates of postfire regeneration in campos de altitude. Biotropica, v. 33, n. 2, p. 282-302. June 2001.

SANTOS, A. C. R. Distribuição altimétrica dos campos de altitude no Parque Nacional do Itatiaia. Monografia - Curso de Geografia da Universidade de Taubaté - SP. 50 p. 2003.

SCARANO, F. R. Structure, Function and Floristic Relationships of Plant Communities in Stressful Habitats Marginal to the Brazilian Atlantic Rainforest, Annals of Botany, v. 90, n. 4, p. 517524. Sept. 2002.

SEGADAS-VIANNA, F. Ecology of the Itatiaia Range, Southeastern Brazil - Altitudinal Zonation of the Vegetation. Arquivos do Museu Nacional, v. 53, p. 7- 30. 1965.

SEGADAS-VIANNA, F.; DAU, L. Ecology of the Itatiaia Range, Southeastern Brazil - Climates and Altitudinal Climatic Zonation. Arquivos do Museu Nacional, v. 53, p. 31-53. 1965.

SILVA, J. C. Diagnóstico das áreas de maior incidência de incêndios florestais em Unidades de Conservação Pertencentes a APA Gama - Cabeça de Veado. 2001. 59 f. Dissertação (Mestrado em Ciências Florestais)-Universidade de Brasília, Brasília, 2001.

SILVA, L.C.V.;ARGENTO, M. S.F.;FERNANDES, M. C. Modelagem ambiental de cenários de potencialidade a ocorrência de incêndios no Parque Nacional do Itatiaia/RJ. In: SIMPÓSIO 
BRASILEIRO DE SENSORIAMENTO REMOTO, 13., 2007, Florianópolis. Anais... Florianópolis, 2007. p. 21-26.

SILVA, V. F.; OLIVEIRA-FILHO, A. T.; VENTURIN, N. Impacto do fogo no componente arbóreo de uma floresta estacional semidecídua no município de Ibituruna, MG, Brasil. Acta Botânica Brasílica. v. 19, n. 4, p. 701-716. abr. 2005

SOARES, R. V. Perfil dos incêndios florestais no Brasil de 1979 a 1987. Brasil Florestal, Brasília, v. 18, n. 02, p. 94-121. 1989.

SOARES, R. V.; SANTOS, J. F. Perfil dos incêndios florestais no Brasil de 1994 a 1997. Floresta, Curitiba, v. 2, n. 32, jul/dez. 2002.

TANIZAKI-FONSECA, K.; E BOHRER, C. B. A O fogo como fator de degradação de ecossistemas de mata Atlântica no estado do Rio de Janeiro. In:
BERGALLO, H. G. et al. (Orgs.). Estratégias e Ações para a Conservação da Biodiversidade no Estado do Rio de Janeiro. Rio de Janeiro: Instituto Biomas, 2009. p. 81-90.

TURNER, M. G.; HARGROVE, W. H.; GARDNER, R. H. Effects of fire on landscape heterogeneity in Yellowstone National Park, Wyoming. Journal of Vegetation Science. v. 5, p. 731-742. 1994.

VELOSO, H. P.; RANGEL-FILHO, A. L. R.; LIMA, J. C. A. Classificação da vegetação brasileira, adaptada a um sistema universal. Rio de Janeiro: IBGE, 1991. 116 p.

VOSGERAU, J. L.; BATISTA, A. C.; SOARES, R. V. Avaliação dos registros de Incêndios Florestais do Estado do Paraná no período de 1991 a 2001. Floresta, Curitiba v. 34, n. 2, p. 193-197, mai/ago. 2006.

Ci. Fl., v. 21, n. 1, jan.-mar., 2011 